52.7\% (r-axSpA/AS: 52.6\%; nr-axSpA: 52.9\%) had inactive disease (ASDAS<1.3; LOCF; Table B). The treatment-emergent adverse event (TEAE) rate/100 patient-years' exposure was 224.2 ; $3.9 \%$ patients discontinued CZP due to TEAEs. No new safety signal was identified. Conclusion: The run-in phase of C-OPTIMISE shows that similar and substantial proportions of patients with $\mathrm{r}$-axSpA/AS and nr-axSpA achieved sustained remission during 48 wks' CZP treatment. No new safety signal was identified.

\begin{tabular}{|c|c|c|c|}
\hline & $\operatorname{axSpA}(\mathrm{N}=736)[\mathrm{a}]$ & $r-a x S p A / A S(n=407)[b]$ & $n r-a x S p A(n=329)[b]$ \\
\hline Age (years), mean (SD) & $32.9(7.0)$ & $33.7(6.8)$ & $32.1(7.1)$ \\
\hline Male, $n(\%)$ & $513(69.7)$ & $318(78.1)$ & $195(59.3)$ \\
\hline Symptom duration (years), mean (SD) [c] & $2.2(1.7)$ & $2.5(1.8)$ & $1.8(1.6)$ \\
\hline HLA-B27 positive, n (\%) & $597(81.1)$ & $354(87.0)$ & $243(73.9)$ \\
\hline Sacroilititis on imaging, $n(\%)[d]$ & $691(93.9)$ & $401(98.5)$ & $290(88.1)$ \\
\hline Prior anti-TNF treatment, $n(\%)$ & $31(4.2)$ & $20(4.9)$ & $11(3.3)$ \\
\hline
\end{tabular}

B) Clinical Outcomes

\begin{tabular}{|c|c|c|c|c|c|c|}
\hline \multirow[b]{2}{*}{$\%$} & \multicolumn{2}{|c|}{ axSpA $(\mathrm{N}=736)$} & \multicolumn{2}{|c|}{ raxspA/AS $(n=407)$} & \multicolumn{2}{|c|}{$n$ rarspp $A(n=329)$} \\
\hline & BL & Wk48 (NRI) & BL & Wk48 (NRI) & BL & Wk48 (NRI) \\
\hline ASAS20 & - & 79.6 & - & 79.9 & - & 79.3 \\
\hline ASAS40 & - & 72.0 & - & 71.3 & - & 72.9 \\
\hline ASAS-PR & - & 57.3 & - & 55.8 & - & 59.3 \\
\hline BASDAI50 & - & 71.7 & - & 71.3 & - & 72.3 \\
\hline Mean [e] & BL & Wk48 (LOCF $[e])$ & $B L$ & Wk48 (LOCF [e]) & BL & Wk48 (LOCF [e]) \\
\hline ASDAS & 3.7 & 1.6 & 3.8 & 1.6 & 3.6 & 1.5 \\
\hline HDA/VHDA,\% & 98.5 & $24.7+$ & 98.5 & 25.8 & 98.5 & $23.2 \pm$ \\
\hline ID, \% & - & $52.7+$ & - & 52.6 & - & $52.9 \pm$ \\
\hline $\mathrm{CII}, \%[\mathrm{f}]$ & - & 76.5 & - & 78.6 & - & 73.9 \\
\hline $\mathrm{MI}, \%[\mathrm{fl}]$ & - & 56.3 & - & 58.7 & - & 53.2 \\
\hline BASDAI & 6.7 & 2.1 & 6.7 & 2.1 & 6.7 & 2.2 \\
\hline BASFI & 5.3 & 1.7 & 5.4 & 1.7 & 5.1 & 1.6 \\
\hline BASMI & 3.1 & 2.3 & 3.5 & 2.6 & 2.7 & 1.9 \\
\hline Nocturnal back pain & 6.9 & 1.8 & 7.0 & 1.8 & 6.8 & 1.8 \\
\hline Fatigue & 7.1 & 2.6 & 7.1 & 2.5 & 7.1 & 2.6 \\
\hline $\operatorname{CRP}(\mathrm{mg} / \mathrm{L})$, median $[\mathrm{g}]$ & 7.8 & 2.0 & 10.7 & 2.0 & 4.5 & 2.0 \\
\hline
\end{tabular}

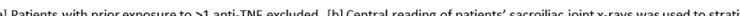

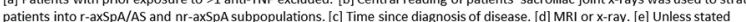

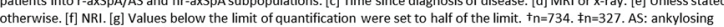
spondylitis; ASAS20/40: $20 \%$ \% $\geq 40 \%$ improvement in Assessment of SpondyloArthritis international Society response criteria; ASAS PR: ASAS Partial Remission; ASDAS: Ankylosing Spondylitis Disease Activity Score; axSPA: axial spondyloarthritis; BASDAI: Bath Anklosing Spondylitis Disease Activty Index; BASDAI 50: $250 \%$ improvement in BASDAl; BASF: Bath Ankylosing Spondylitis

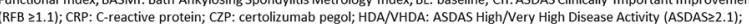
ID: ASDAS Inactive Disease (ASDAS <1.3); LOCF: last observation carried forward; MI: ASDAS Major Improvement (RFB 22.0);

MRI: magnetic resonance imaging; $\mathrm{nr}$-axSpA: non-radiographic axSpA; NRI: non-responder imputation; r-axSpA: radiographic axSpA;
RFB: reduction from baseline; WK: week

Acknowledgement: We thank the patients who participated. This study was funded by UCB Pharma, medical writing by Hinal Tanna, Costello Medical, UK.

Disclosure of Interests: Robert B.M. Landewé: None declared, Désirée van der Heijde Consultant for: AbbVie, Amgen, Astellas, AstraZeneca Bristol-Myers Squibb, Boehringer Ingelheim, Celgene, Daiichi, Eli-Lilly, Galapagos, Gilead, GlaxoSmithKline, Janssen, Merck, Novartis, Pfizer, Regeneron, Roche, Sanofi, Takeda, Union Chimique Belge, maxime dougados Grant/research support from: Eli Lilly and Company, Pfizer, AbbVie, and UCB Pharma, Consultant for: Eli Lilly and Company, Pfizer, AbbVie, and UCB Pharma, Xenofon Baraliakos Grant/research support from: AbbVie, Boehringer Ingelheim, Bristol-Myers Squibb, Celgene, Centocor, Chugai, Janssen, MSD, Novartis, Pfizer Inc, Roche and UCB, Grant/research support from: AbbVie, Pfizer, Merck Sharp \& Dohme, UCB Pharma, Novartis, Consultant for: AbbVie, Bristol-Myers Squibb, Boehringer Ingelheim, Celgene, Chugai, Janssen Biologics, Novartis, Pfizer, UCB Pharma, Galapagos, Speakers bureau: AbbVie, Chugai, Janssen, Novartis, Pfizer, UCB Pharma, Filip van den Bosch Consultant for: AbbVie, BMS, Galapagos, Janssen, Lilly, Merck, Novartis, Pfizer and UCB, Speakers bureau: AbbVie, BMS, Janssen, Lilly, Merck, Novartis, Pfizer and UCB., Karl Gaffney Grant/research support from: Abbvie, Pfizer, Consultant for: Abbvie, Lilly, Novartis, UCB, Speakers bureau: Abbvie, Biogen, Gilead, Lilly, Novartis, UCB, Natasha de Peyrecave Employee of: Employee of UCB Pharma, Lars Bauer Employee of: Employee of UCB Pharma, Bengt Hoepken Employee of: Employee of UCB Pharma, Karen Thomas Employee of: Contracted Statistician of UCB Pharma., Lianne S. Gensler Grant/research support from: Abbvie, Amgen, UCB Pharma, Consultant for: Novartis, Lilly, Janssen

DOI: 10.1136/annrheumdis-2019-eular.3053

\section{FRI0398 IXEKIZUMAB IS EFFECTIVE IN THE TREATMENT OF RADIOGRAPHIC AXIAL SPONDYLOARTHRITIS REGARDLESS OF THE LEVEL OF C-REACTIVE PROTEIN OR MAGNETIC RESONANCE IMAGING SCORES: 16-WEEK DATA FROM COAST-V AND COAST- W}

Walter P. Maksymowych ${ }^{1}$, Gaia Gallo ${ }^{2}$, Rebecca Bolce ${ }^{2}$, Fangyi Zhao $^{2}$, Vladimir Geneus ${ }^{2}$, Mikkel Ǿstergaard ${ }^{3}$, Kurisu Tada ${ }^{4}$, Atul Deodhar ${ }^{5}$, Lianne S. Gensler6. ${ }^{1}$ University of Alberta, Department of Medicine, Edmonton, Canada; ${ }^{2}$ Eli Lilly and Company, Indianapolis, United States of America; ${ }^{3}$ University of Copenhagen, Copenhagen Center for Arthritis Research, Center for Rheumatology and Spine Diseases, Rigshospitalet, Denmark; ${ }^{4}$ Juntendo University School of Medicine, Department of Internal Medicine and Rheumatology, Tokyo, Japan; ${ }^{5}$ Oregon Health and Science University, Rheumatology Clinica Division of Arthritis and Rheumatic Diseases, Portland, United States of America; ${ }^{6}$ University of California at San Francisco, School of Medicine, San Francisco, United States of America

Background: Radiographic axial spondyloarthritis ( $r$-axSpA) is a chronic inflammatory disease of the axial skeleton, and interleukin (IL)-17 plays an important role in the pathogenesis. Elevated C-reactive protein (CRP) levels in serum predict response to tumor necrosis factor inhibitors (TNFi $^{1-4}$ but not to secukinumab. ${ }^{5}$ The role of baseline spine magnetic resonance imaging (MRI) as a predictor of response has not been investigated for IL-17 inhibitors.

Objectives: To evaluate response rates at week (wk) 16 with ixekizumab (IXE), an IL-17A antagonist, in patients with ankylosing spondylitis (AS)/raxSpA and elevated or normal/low inflammation as measured by CRP or spinal MRI.

Methods: Two Phase 3, randomized, double-blind, placebo (PBO)-controlled trials (COAST-V, NCT02696785; COAST-W, NCT02696798) enrolled patients who were biologic-naive or TNFi-experienced, respectively, with active disease (Bath Ankylosing Spondylitis Disease Activity Index [BASDAI] $>4$ and spinal pain $>4$ on a numeric rating scale) and an established diagnosis of $r$-axSpA and fulfilling Assessment of SpondyloArthritis international Society (ASAS) criteria (sacroiliitis on radiograph by modified New York [mNY] criteria and $\geq 1$ spondyloarthritis feature). All patients fulfilling ASAS criteria also fulfilled $m N Y$ criteria for $A S$. Patients were treated with IXE (80 mg every 2 or 4 wks [Q2W, Q4W]) or PBO; adalimumab (40 mg Q2W) was an active reference arm in COAST-V. We examined ASAS 40\% (ASAS40) response rates at wk 16 for the intentto-treat population by $\mathrm{CRP}$ ( $\leq 5$ or $>5 \mathrm{mg} / \mathrm{L}$ ) or MRI spine inflammation (Spondyloarthritis Research Consortium of Canada [SPARCC] spine score, $<2$ or $\geq 2$ ). Baseline spine MRI was available in $96 \%$ of patients in COAST-V and $51 \%$ of patients in COAST-W; scoring was done by central readers. Higher scores reflect greater baseline disease activity. Sacroiliac joint MRls were not assessed. Missing data for ASAS40 were imputed by nonresponder imputation.

Results: In the COAST-V/W integrated dataset that combined biologicnaive and TNFi-experienced populations, significantly more patients treated with IXE achieved ASAS40 response at wk 16 than with PBO in the elevated $(>5 \mathrm{mg} / \mathrm{L}$ ) baseline CRP group $(39.3 \%, 42.5 \%$, and $16.7 \%$ for IXE Q4W, IXE Q2W and PBO, respectively; $p<.001$ for IXE Q4W, IXE Q2W vs $\mathrm{PBO})$ and in the normal $(\leq 5 \mathrm{mg} / \mathrm{L})$ baseline CRP group $(27.4 \%$ $35.2 \%$, and $12.3 \%$ for IXE Q4W, IXE Q2W and $\mathrm{PBO}$, respectively; $\mathrm{p}<.05$ for IXE Q4W, $\mathrm{p}<.01$ for IXE Q2W vs PBO, Fig 1), and the magnitude of response with IXE between elevated vs normal CRP groups was not statistically significant. Notably, a significantly higher proportion of patients achieved ASAS40 at wk 16 with IXE than with $\mathrm{PBO}$, regardless of whether MRI spine SPARCC scores were <2 (40\%, 51.7\%, and $15.5 \%$ for IXE Q4W, IXE Q2W and PBO, respectively; $\mathrm{p}<.01$ for IXE Q4W $\mathrm{p}<.001$ for IXE Q2W vs PBO) or $\geq 2(44.3 \%, 46.6 \%$, and $18.7 \%$ for IXE Q4W, IXE Q2W and $\mathrm{PBO}$, respectively; $\mathrm{p}<.001$ for IXE Q4W, IXE Q2W vs PBO, Fig 1).

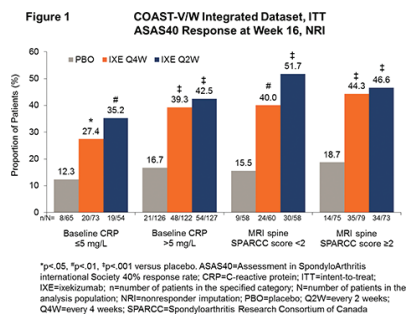


Conclusion: IXE demonstrated rapid efficacy in the treatment of $A S / r-$ axSpA at wk 16 irrespective of baseline serum CRP levels or spinal MRI score.

\section{REFERENCES:}

[1] Inman, et al. 2008

[2] Braun, et al. 2016

[3] de Vries, et al. 2009

[4] Vastesaeger, et al. 2011

[5] Braun, et al. 2018

Disclosure of Interests: Walter P. Maksymowych Grant/research support from: Abbvie, Pfizer, Novartis, Consultant for: Abbvie, Boehringer, Celgene, Lilly, Novartis, Pfizer, UCB, Speakers bureau: Honoraria from Abbvie, Boehringer, Celgene, Lilly, Novartis, Pfizer, UCB for speaking events but I am not in any speaker's bureau., Gaia Gallo Shareholder of: Eli Lilly and Company, Employee of: Eli Lilly and Company, Rebecca Bolce Shareholder of: Eli Lilly and Company, Employee of: Eli Lilly and Company, Fangyi Zhao Shareholder of: Eli Lilly and Company, Employee of: Eli Lilly and Company, Vladimir Geneus Shareholder of: Eli Lilly and Company, Employee of: Eli Lilly and Company, Mikkel Ǿstergaard Grant/ research support from: Abbvie, Celgene, Centocor, Merck, Novartis, Consultant for: Abbvie, BMS, Boehringer-Ingelheim, Celgene, Eli Lilly, Hospira, Janssen, Merck, Novartis, Novo, Orion, Pfizer, Regeneron, Roche, and UCB, Speakers bureau: Abbvie, BMS, Boehringer-Ingelheim, Celgene, Eli Lilly, Hospira, Janssen, Merck, Novartis, Novo, Orion, Pfizer, Regeneron, Roche, and UCB, Kurisu Tada Grant/research support from: Eli Lilly, Atul Deodhar Grant/research support from: AbbVie, Amgen, Eli Lilly, GSK, Janssen, Novartis, Pfizer, and UCB, Consultant for: AbbVie, Amgen, BMS, Eli Lilly, Janssen, Novartis, Pfizer, and UCB, Lianne S. Gensler Grant/research support from: Abbvie, Amgen, UCB Pharma

Consultant for: Novartis, Lilly, Janssen

DOI: 10.1136/annrheumdis-2019-eular.1466

\section{FRI0399 INFLIXIMAB TROUGH LEVELS AND DISEASE ACTIVITY PREDICT EARLY CLINICAL RESPONSE IN PATIENTS WITH AXIAL SPONDYLOARHTRITIS}

ANA MARTÍNEZ-FEITO ${ }^{1}$, Chamaida Plasencia ${ }^{2}$, Borja Hernández-Breijo ${ }^{3}$, Victoria Navarro-Compán ${ }^{2}$, Diana Peiteado ${ }^{2}$, Alejandro Villalva², Laura Nuño ${ }^{2}$ Irene Monjo ${ }^{2}$, Cristina Diego ${ }^{1}$, Dora Pascual-Salcedo ${ }^{3}$, Alejandro Balsa ${ }^{2} .{ }^{1}$ Hospital La Paz-madrid, Immunology, Madrid, Spain; ${ }^{2}$ Hospital La Paz-madrid, Rheumatology, Madrid, Spain; ${ }^{3} / d i P A Z$, Immuno-Rheumatology research group, Madrid, Spain

Background: Infliximab (Ifx) has proven to be effective in patients with axial spondyloarthritis (axSpA). Several variables may affect pharmacokinetic-pharmacodynamic of $\mathrm{Ifx}$ and its relation with clinical response, such as: disease activity (inflammatory burden), the development of anti-drug antibodies (ADA) and the concomitant use of conventional synthetic disease modifying anti-rheumatic drugs The improvement of patient's management by achieving optimal serum drug concentration associated with good clinical response is the main goal of therapeutic drug monitoring (which can be helpful in the prediction of clinical response to biological treatment.

Objectives: To identify clinical and serological variables at early stages of treatment that can predict clinical response in patients with axSpA treated with Ifx.

Methods: Observational study including 81 patients with axSpA recruited from the axSpA-Paz cohort treated with Ifx and monitored during 24 weeks (W). Serum Ifx levels and ADA were measured by capture ELISA and by bridging ELISA respectively at baseline, W2, W6, W14 and W24. Disease activity was assessed at baseline and W24 by the Ankylosing Spondylitis Disease Activity Score (ASDAS) and clinical response was defined by $\triangle A S D A S \geq 1.1$ (clinically important improvement). The association between clinical response at W24 and clinical and serological variables was evaluated by univariable and multivariable logistic regression analyses. Serum Ifx levels at W2, 6 and 14 as a categorical variable (above 0 under the corresponding median value of levels at each time week), age, sex, HLA-B27, methotrexate (MTX), sulfasalazine, body mass index, smoke status, prednisone, C-reactive protein and ASDAS at baseline were included as independent variables. Receiver operating characteristic (ROC) curves for the outcome of clinical response after 24 weeks of treatment were employed to determine the best cut-off values for the predictors (serum Ifx concentrations and baseline ASDAS). Ifx survival was evaluated through Kaplan-Meier curves.
Results: In the univariable analyses, higher serum Ifx trough levels at W14 (OR: 3.9; 95\%Cl: 1.5-10.4); higher baseline ASDAS (OR: 1.9; 95\% Cl: 1.1-3.1) and MTX use (OR: 3.3 ; $95 \% \mathrm{Cl}$ : 1.2-8.7) were associated with a better clinical response at W24. Patients with concomitant MTX had higher serum Ifx trough levels (median and IQR) than patients without MTX and these differences were significant at W6: 26.37(16-41.4) versus 16.9(11.4-26.9); $\mathrm{p}=0.008$; at $\mathrm{W} 14$ : $8.4(5.4-13.9)$ versus $4.1(1.8-7.8)$; $\mathrm{p}=0.003$ and at W22: $5.1(2.2-8.3)$ versus $3.1(0.6-5.4) ; \mathrm{p}=0.006$ and; respectively). In the multivariable analysis, higher ASDAS at baseline (OR: $1.8 ; \mathrm{Cl}$ 95\%: 1.1-3.0) and higher serum Ifx trough levels at $\mathrm{W} 14$ (OR: 3.6; $\mathrm{Cl} 95 \%$ : 1.3-10.4) remained significantly associated. Serum Ifx concentration at $\mathrm{W} 14 \geq 6.7 \mu \mathrm{g} / \mathrm{mL}$ and a disease activity score at baseline $\geq 3.5$ were found to be associated with higher $\triangle$ ASDAS at W24 (OR: $16 ; 95 \% \mathrm{Cl}: 3.6-71.7$ ). No patient with Ifx levels at $\mathrm{W} 14 \geq 6.7 \mu \mathrm{g} /$ $\mathrm{mL}$ developed ADA during the 24 weeks follow up. The combination of both variables was used to predict clinical response with a sensitivity of $87.5 \%$, specificity of $69.6 \%$, PPV of $75 \%$ and NPV of $84.2 \%$.

Conclusion: Elevated baseline ASDAS and high serum Ifx trough levels at W14 are associated with better clinical response at 24 weeks in patients with axSpA under Ifx therapy. A predictive model based on these variables is suggested to identify early responders to Ifx treatment. Disclosure of Interests: ANA MARTÍNEZ-FEITO: None declared, Chamaida Plasencia Speakers bureau: Pfizer, MSD, Borja Hernández-Breijo: None declared, Victoria Navarro-Compán: None declared, Diana Peiteado: None declared, Alejandro Villalva: None declared, Laura Nuño: None declared, Irene Monjo: None declared, Cristina Diego: None declared, DORA PASCUAL-SALCEDO Grant/research support from: Pfizer, Speakers bureau: Pfizer, Abbvie, Takeda, Alejandro Balsa Grant/research support from: Abbvie, Pfizer, Novartis, BMS, Nordic, Sanofi, Consultant for: Abbvie, Pfizer, Novartis, BMS, Nordic, Sanofi, Sandoz, Lilly, Paid instructor for: Pfizer, Speakers bureau: Pfizer, Novartis, UCB, Nordic, Sanofi, Sandoz, Lilly

DOI: 10.1136/annrheumdis-2019-eular.3984

\section{FRI0400 LONG-TERM SAFETY OF IXEKIZUMAB IN PATIENTS WITH RADIOGRAPHIC AXIAL SPONDYLOARTHRITIS/ ANKYLOSING SPONDYLITIS: AN INTEGRATED ANALYSIS OF COAST-V AND COAST-W}

Helena Marzo-Ortega ${ }^{1}$, Eduardo Mysler ${ }^{2}$, Tetsuya Tomita $^{3}$, Jeffrey Lisse ${ }^{4}$, Silvia Santisteban ${ }^{4}$, Sandra Garces ${ }^{4}$, Wen Xu ${ }^{4}$, Martin Rudwaleit ${ }^{5}$, Carlo Salvarani ${ }^{6}$, Sergio Schwartzman ${ }^{7} .{ }^{1}$ NIHR Leeds Biomedical Research Centre, Leeds Teaching Hospitals Trust and LIRMM, Univ of Leeds, Leeds, United Kingdom; ${ }^{2}$ Organización Médica de Investigación, Buenos Aires, Argentina; ${ }^{3}$ Osaka Univ Graduate School of Medicine, Osaka, Japan; ${ }^{4}$ Eli Lilly and Company, Indianapolis, United States of America; ${ }^{5}$ Klinikum Bielefeld, Bielefeld, Germany;

${ }^{6}$ Azienda USL-IRCCS and Univ di Modena e Reggio Emilia, Reggio Emilia, Italy;

${ }^{7}$ The Hospital for Special Surgery, New York, United States of America

Background: The efficacy and safety of ixekizumab (IXE) in patients with radiographic axial spondyloarthritis $(\mathrm{r}$-axSpA) were investigated in the COAST trial program.

Objectives: To report the long-term safety of IXE in r-axSpA patients using integrated safety data from the COAST trials program.

Methods: Safety data for r-axSpA patients treated with IXE were integrated from COAST-V (biologic-naïve; NCT02696785) and COAST-W (Inadequate responders or intolerant to 1 or 2 TNF inhibitors; NCT02696798) studies. Patients fulfilled ASAS criteria for $r$-axSpA and $\mathrm{mNY}$ criteria for ankylosing spondylitis. Trial eligibility criteria were previously reported. ${ }^{1,2}$ In these studies, participants were randomized to placebo $(n=191)$, adalimumab $(n=90$, active reference arm, COAST-V only), or ixekizumab $(n=376)$. Study participants initially randomized to IXE in both trials were treated with a starting dose $(80-\mathrm{mg}$ or $160-\mathrm{mg})$ and then 80-mg IXE every 2 weeks (IXEQ2W) or 4 weeks (IXEQ4W). Patients initially treated with placebo or adalimumab were re-randomized at Week 16 to receive either IXEQ2W or IXEQ4W following a 160-mg starting dose. The analysis population included all ixekizumab-exposed patients in both trials. Incidence rates (IR) per 100 person years with 95\% confidence intervals $(\mathrm{Cl})$ and the number of patients are reported. Adverse Event (AE) codes were derived from MedDRA (v21.0). Integrated safety data presented here include all data collected between May 6. 2016 and Sept. 20, 2018.

Results: The integrated population consisted of 641 patients with 749.6 total patient-years of exposure to IXE. Mean follow up time was 427 days. Mean baseline age was $43.8 \pm 12.3$ years. Mean and median baseline disease symptom duration (since onset) were $17.2 \pm 10.8$ years and 15.5 years (Min: 1.1, Max: 56.2), respectively. Safety data are presented in Table 1. Among these patients, $489(76.3 \%)$ reported $\geq 1$ treatment 